\title{
In Vivo Visualization of Active Polysynaptic Circuits With Longitudinal Manganese-Enhanced MRI (MEMRI)
}

\author{
Suellen Almeida-Corrêa ${ }^{1}$, Michael Czisch ${ }^{2}$ and Carsten T. Wotjak ${ }^{1 *}$ \\ ${ }^{1}$ Department of Stress Neurobiology \& Neurogenetics, Max Planck Institute of Psychiatry, Munich, Germany, ${ }^{2}$ Core Unit \\ Neuroimaging, Max Planck Institute of Psychiatry, Munich, Germany
}

\section{OPEN ACCESS}

Edited by: Keigo Hikishima,

Okinawa Institute of Science and

Technology, Japan

Reviewed by:

Benito de Celis Alonso,

Benemérita Universidad Autónoma de

Puebla, Mexico

Vassiliy Tsytsarev,

University of Maryland, College Park,

United States

*Correspondence:

Carsten T. Wotjak

wotjak@psych.mpg.de

Received: 05 April 2018

Accepted: 30 April 2018

Published: 22 May 2018

Citation:

Almeida-Corrêa S, Czisch M and Wotjak CT (2018) In Vivo Visualization of Active Polysynaptic Circuits With Longitudinal Manganese-Enhanced MRI (MEMRI).

Front. Neural Circuits 12:42. doi: 10.3389/fncir.2018.00042
Manganese-enhanced magnetic resonance imaging (MEMRI) is a powerful tool for in vivo non-invasive whole-brain mapping of neuronal activity. $\mathrm{Mn}^{2+}$ enters active neurons via voltage-gated calcium channels and increases local contrast in $T_{1}$-weighted images. Given the property of $\mathrm{Mn}^{2+}$ of axonal transport, this technique can also be used for tract tracing after local administration of the contrast agent. However, MEMRI is still not widely employed in basic research due to the lack of a complete description of the $\mathrm{Mn}^{2+}$ dynamics in the brain. Here, we sought to investigate how the activity state of neurons modulates interneuronal $\mathrm{Mn}^{2+}$ transport. To this end, we injected mice with low dose $\mathrm{MnCl}_{2}$ 2. (i.p., $20 \mathrm{mg} / \mathrm{kg}$; repeatedly for 8 days) followed by two MEMRI scans at an interval of 1 week without further $\mathrm{MnCl}_{2}$ injections. We assessed changes in $\mathrm{T}_{1}$ contrast intensity before (scan 1) and after (scan 2) partial sensory deprivation (unilateral whisker trimming), while keeping the animals in a sensory enriched environment. After correcting for the general decay in $\mathrm{Mn}^{2+}$ content, whole brain analysis revealed a single cluster with higher signal in scan 1 compared to scan 2: the left barrel cortex corresponding to the right untrimmed whiskers. In the inverse contrast (scan 2 > scan 1), a number of brain structures, including many efferents of the left barrel cortex were observed. These results suggest that continuous neuronal activity elicited by ongoing sensory stimulation accelerates $\mathrm{Mn}^{2+}$ transport from the uptake site to its projection terminals, while the blockage of sensory-input and the resulting decrease in neuronal activity attenuates $\mathrm{Mn}^{2+}$ transport. The description of this critical property of $\mathrm{Mn}^{2+}$ dynamics in the brain allows a better understanding of MEMRI functional mechanisms, which will lead to more carefully designed experiments and clearer interpretation of the results.

Keywords: manganese-enhanced MRI, neuroimaging, brain connectomics, $\mathrm{Mn}^{2+}$ transport, barrel-cortex, whiskers, sensory deprivation

\section{INTRODUCTION}

The dissection of neuronal pathways involved in specific brain networks underlying distinct behavioral outputs is of outmost interest to modern neuroscience. Currently employed methods in basic research include local brain injections of neuronal anterograde (Gerfen and Sawchenko, 1984; Veenman et al., 1992) and retrograde tracers (Arvidson, 1977; Schmued and Fallon, 1986; Quattrochi et al., 1989) or viral vectors (Wickersham et al., 2007; Zeng et al., 2017; Zingg et al., 2017). They rely on the investigation of the pathways post-mortem, via histological analysis of 
brain slices or cleared brains when employing CLARITY based protocols for example (Chung et al., 2013). Moreover, these methods are limited to pre-defined regions of interest, given that they require targeted brain injections. A lot has been learned about neuronal circuits employing these tools, however, a noninvasive technique that would allow follow-up investigations comparing the same animals overtime is still desirable. Here, we focus on manganese-enhanced magnetic resonance imaging (MEMRI) as a powerful alternative.

MEMRI has the potential to non-invasively map whole-brain activity and identify structures related to a specific task (Chen et al., 2007, 2013; Bissig and Berkowitz, 2009; Eschenko et al., 2010; Bangasser et al., 2013; Hoch et al., 2013; Tang et al., 2016; Laine et al., 2017) since $\mathrm{Mn}^{2+}$ enters active neurons through voltage-gated calcium channels (Drapeau and Nachshen, 1984) (e.g., $\mathrm{Ca}_{\mathrm{v}} 1.2$; Bedenk et al., 2018), and is transiently kept intracellularly (Gavin et al., 1990). $\mathrm{Mn}^{2+}$ shortens the $\mathrm{T}_{1}$ relaxation time of water (Spiller et al., 1988; Nordhøy et al., 2004) leading to a contrast increase in $\mathrm{T}_{1}$-weigthed images (Pautler and Koretsky, 2002). Brain structures that accumulate $\mathrm{Mn}^{2+}$ can be detected as hotspots in $\mathrm{T}_{1}$-weighted images, indicating higher neuronal activity in these areas (Lin and Koretsky, 1997). This technique modality is also referred to as activation-induced manganese-dependent MRI (AIM-MRI) (Tambalo et al., 2009). If the integrity of the blood-brain barrier is disrupted, even dynamic accumulation of $\mathrm{Mn}^{2+}$ can be observed in a single experimental session (DAIM-MRI) (Aoki et al., 2002).

MEMRI is also used for tract-tracing (for review see Pautler, 2004), since $\mathrm{Mn}^{2+}$ can be axonally transported to neuronal terminals after local $\mathrm{MnCl}_{2}$ administration (Sloot and Gramsbergen, 1994; Pautler et al., 1998), revealing the underlying circuitry of the injection target. During this process, $\mathrm{Mn}^{2+}$ may cross one or more synapses (Pautler et al., 1998).

We have recently shown that $\mathrm{Mn}^{2+}$ preferentially accumulates in projection terminals of the active entrance sites after systemic $\mathrm{MnCl}_{2}$ administration (Bedenk et al., 2018). This feature of $\mathrm{Mn}^{2+}$ allows for the combination of activity-induced dissection of structures related to a specific behavior, and the connectomics analysis of the neuronal pathways underlying these brain structures. In that way, MEMRI does not only provide a snapshot of the structures active in response to a given task, but also reveals the downstream connectivity of these brain structures. This results in a functional connectivity map. Furthermore, the possibility of scanning the same animals at different time points allows for dynamic investigations of the functional circuitry in a within-subject fashion, thus reducing the number of required subjects while increasing the power of such studies (3-Rs principle for ethical use of animals in testing).

Despite those features, MEMRI is still not widely used, partially due to toxic side effects, but also due to insufficient information regarding $\mathrm{Mn}^{2+}$ dynamics in the brain, confounding the interpretation of the results. Some properties, such as activitydependent entrance into cells via voltage-gated calcium channels (Drapeau and Nachshen, 1984), transient intracellular storage (Gavin et al., 1990), and preferential accumulation in projection terminals (Bedenk et al., 2018) have previously been reported. However, other properties such as the influence of neuronal activity state on intracellular $\mathrm{Mn}^{2+}$ storage and axonal transport have been debated in the literature with inconclusive findings. Therefore, a complete description of $\mathrm{Mn}^{2+}$ dynamics in the brain is still lacking.

To address this, we conducted a longitudinal within-subject study to investigate whether, following systemic injections of $\mathrm{MnCl}_{2}$, the transport of $\mathrm{Mn}^{2+}$ is dependent on neuronal activity elicited by sensory stimulation. As a model pathway for this study we chose the whiskers-barrel cortex system, based on its well-described and defined connectivity (for examples see Chmielowska et al., 1989; Aronoff et al., 2010; Zakiewicz et al., 2014) and the property of sensory stimulation by whisking resulting in a strong and specific increase on neuronal activity at the corresponding contralateral barrel cortex (Woolsey and Van der Loos, 1970; Axelrad et al., 1976; Peron et al., 2015). As such, we aimed to compare the contrast patterns observed with MEMRI (i) following systemic $\mathrm{MnCl}_{2}$ injections in mice with intact whiskers in enriched sensory housing conditions, and (ii) after the same mice were partially sensory deprived (unilateral whisker trimming). We hypothesized that ongoing sensory input would lead to accelerated clearance of $\mathrm{Mn}^{2+}$ in the corresponding barrel cortex with a concomitant relative increase in $\mathrm{Mn}^{2+}$ accumulation in efferent structures.

\section{MATERIALS AND METHODS}

All experiments were carried out according to the European Community Council Directive 2010/63/EEC. All experimental procedures were approved by the local government of Upper Bavaria (AZ 142-12). Every effort was done to keep the number of experimental subjects at a minimum and to avoid animal suffering.

\section{Animals}

Adult male C57BL/6N mice ( $n=9$ ) from our local breeding stock (Max Planck Institute of Biochemistry, Martinsried, Germany) were kept in groups of 3 per cage with food and water ad libitum, under a $12 \mathrm{~h}$ dark/light inverted cycle (lights on at 07h30), in a room with controlled temperature and humidity. After transfer to the local animal facility at the Max Planck Institute of Psychiatry, mice were allowed to get accustomed to the holding conditions (standard macrolon cages type II; $267 \times$ $207 \times 140 \mathrm{~mm}$, floor area $370 \mathrm{~cm}^{2}$; Tecniplast, Italy) for at least 10 days before experiments started. Mice were 3 to 4 months old at the time of experiments. Intraperitoneal injections described next were conducted between $16 \mathrm{~h} 00$ and $20 \mathrm{~h} 00$.

\section{Drugs}

- $\mathrm{MnCl}_{2} \times 4 \mathrm{H}_{2} \mathrm{O}$ (Sigma-Aldrich, Steinheim, Germany) was dissolved in $0.9 \% \mathrm{NaCl}$ to a final concentration of $50 \mathrm{mM}$ (4947.5 $\mathrm{mg}-500 \mathrm{~mL}$ saline). The $\mathrm{pH}$ was adjusted to 6.95 with $\mathrm{HCl}$ and $\mathrm{NaOH}$.

- Ketamine + xylazine solution: $138 \mathrm{mg}$ of ketamine and $6.8 \mathrm{mg}$ of xylazine $/ 10 \mathrm{~mL}$ solution $(0.9 \% \mathrm{NaCl})$. 


\section{Experimental Procedures}

Mice (3/cage) were housed in large type III cages $(425 \times 266$ $\times 155 \mathrm{~mm}$, floor area $820 \mathrm{~cm}^{2}$; Tecniplast, Italy) enriched with extra nesting material, plastic hair curlers of two different sizes (2 big, $36 \mathrm{~mm}$ radius; 3 medium, $36 \mathrm{~mm}$ radius), used as texturized tunnels (textures on the inner and outer part), and a hanging thread at the metal lid with a another small hair curler/tunnel ( $28 \mathrm{~mm}$ radius). Mice were kept in the same group under this 8 . condition for 8 days, until scanned (scan 1), followed by another 7 days of enriched housing and a second scan (scan 2).

All mice received intraperitoneal injections of $20 \mathrm{mg} / \mathrm{kg}$ $\mathrm{MnCl}_{2}$ (Sigma-Aldrich, Steinheim, Germany) every $24 \mathrm{~h}$ for eight consecutive days ( $8 \times 20 / 24$ h), in order to minimize physiological side effects (adapted from Grünecker et al., 2010; Bedenk et al., 2018). Mice were always weighted immediately before injections to monitor animal's health status and to guarantee the correct dose would be injected every day.

On day 8 , animals (3 per day) were individually anesthetized with a mixture ketamine and xylazine (i.p., injection of 0.1 $\mathrm{mL} / 10 \mathrm{~g}$ mice) and transferred to the MRI room. With ketamine we aimed to block NMDA receptors (Anis et al., 1983) and thus, to avoid further $\mathrm{Mn}^{2+}$ neuronal entrance (Itoh et al., 2008) during the transport of the animals between rooms. For the scanning procedure, see below.

Immediately after scan 1, and still under sedation, animals had all their whiskers trimmed close to the skin on the left side of the snout. The right side was untouched. After trimming, animals were put back in the enriched cages. The trimming procedure was repeated every 2 days (under light isoflurane anesthesia) to avoid re-growth of the whiskers. After scan 1, animals received no further $\mathrm{MnCl}_{2}$ injections.

On the last day of enrichment after scan 1, animals ( 3 per day) were again individually anesthetized with a mixture of ketamine and xylazine (i.p., injection of $0.1 \mathrm{~mL} / 10 \mathrm{~g}$ mice) and transferred to the MRI room for scan 2. For graphic representation of the experimental design see Figure 1A.

\section{Manganese-Enhanced Magnetic Resonance Imaging (MEMRI)}

Twelve to twenty-four hours after the last of 8 daily $\mathrm{MnCl}_{2}$ injections, a first MRI scanning took place (scan 1). Seven days after scan 1, the second MRI scanning took place (scan 2).

All MEMRI experiments were conducted on a 7T Avance Biospec 70/30 scanner (Bruker BioSpin, Ettlingen, Germany). In brief, essentially as described before (Bedenk et al., 2018), mice were fixed in supine position on a saddle-shaped receive-only coil. Head fixation was achieved using a stereotactic device and the frontal teeth were fixed with a surgical fiber. Once fixed in the coil, mice were kept anesthetized with an isofluraneoxygen mixture (1.0-1.5 vol \%, with an oxygen flow of 1.2-1.4 $\mathrm{L} / \mathrm{min}$ ) (Delta Select, Germany). A rectal thermometer was used for body temperature monitoring (Thermalert TH-5, Physitemp Instruments, USA). Body temperature was kept between 36.5 and $37.5^{\circ} \mathrm{C}$ using a water-based heating pad. Pulse rate was continuously monitored by a plethysmographic pulse oxymeter (Nonin 8600V, Nonin Medical Inc., USA).
$\mathrm{T}_{1}$-weighted $(\mathrm{T} 1 \mathrm{w})$ brain images were acquired using a $3 \mathrm{D}$ gradient echo pulse sequence $[\mathrm{TR}=50 \mathrm{~ms}, \mathrm{TE}=3.2 \mathrm{~ms}$, matrix size $=128 \times 106 \times 106$ zero filled to $128 \times 128 \times 128$, field of view $($ FOV $)=16 \times 16 \times 18 \mathrm{~mm}^{3}$, number of averages $=10$, resulting in a spatial resolution of $\left.125 \times 125 \times 140.6 \mu \mathrm{m}^{3}\right]$.

\section{MRI Data Post-processing}

Images were reconstructed in Paravision (Bruker, BioSpin, Ettlingen, Germany) and transferred to standard ANALYSE format. Further post-processing was performed using SPM 8 (www.fil.ion.ucl.ac.uk/spm). T1w-images were bias-corrected using the algorithm implemented in SPM8, minimizing the entropy of the image histogram. In this way we could remove intensity gradients introduced by differences in the distance between surface receiver coil and the brain structures (Milchenko et al., 2006). For each individual subject the brain was then extracted using the RATS software (https://www.estima.com/ ratsmain.shtml). Images were spatially normalized in two steps: In the first step, we generated a study-specific group template. For this purpose, we initially normalized all individual brain extracted images to a representative single subject image of good quality. The study-specific template image was then calculated as the mean image of all normalized images of this first step. In a second normalization step, this study-specific template was then used as the new target image for normalization. Doing so, we aimed at minimizing individual regional discrepancies in the final normalized images (Huang et al., 2010). Finally, all normalized images were smoothed with a Gaussian kernel of eight-times the image resolution $\left(1.0 \times 1.0 \times 1.124 \mathrm{~mm}^{3}\right.$ at full-width half maximum). Data were analyzed using a paired $t$-test (scan 1 and scan 2), along with cerebrospinal fluid (CSF) intensities as a nuisance regressor. To account for unspecific global intensity changes due to $\mathrm{Mn}^{2+}$ wash-out between the two measurements (Grünecker et al., 2013), global image intensities were added as another nuisance regressor. Calculation of the global mean regressor was automatically performed in the generation of the ANCOVA model in SPM8: the global mean is calculated as the mean intensity of all voxel inside the standard analysis mask. By default, this mask includes all voxels which show an intensity larger than $1 / 8^{*}$ (mean of all image voxels).

\section{Definition of Brain Structures}

All the brain structures shown in Figure 1 and listed in Table 1 were defined using the Allen Mouse Brain Atlas (Lein et al., 2006) (http://mouse.brain-map.org/experiment/ thumbnails/100048576?image_type=atlas) as a reference. The only exception is the "islands of Calleja," defined based on "10. The Mouse Brain in Stereotaxic Coordinates" (Franklin and Paxinos, 2007).

\section{Statistics and Data Presentation}

We interrogated the contrast scan $1>$ scan 2 using a strict family-wise error corrected threshold of $\mathrm{p}_{\mathrm{FWE} \text {,cluster }}<0.05$, with a collection threshold of puncorrected $<0.001$ (Woo et al., 2014), which is in accordance with other MEMRI studies (Lutkenhoff et al., 2012; Laine et al., 2017). Due to expected dilution of $\mathrm{Mn}^{2+}$ concentrations after cessation of the $\mathrm{MnCl} 2$ injections, relative 


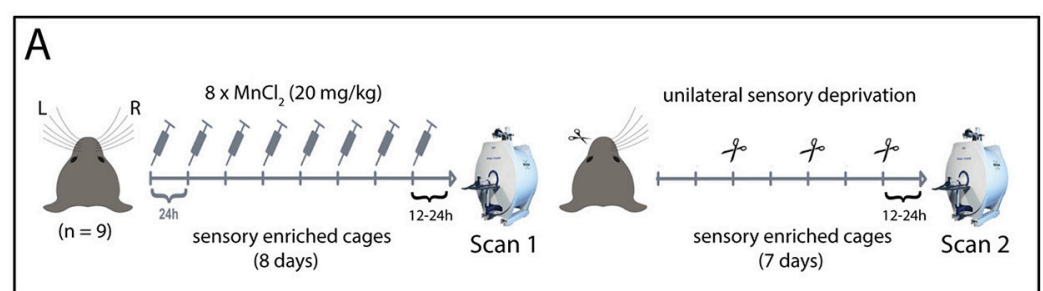

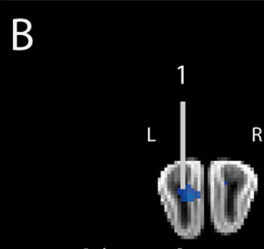

[plate \#16]

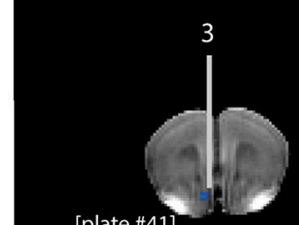

[plate \#41]

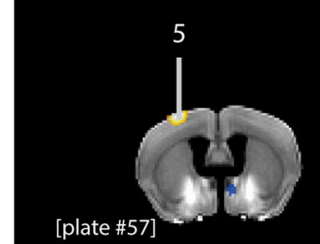

[plate \#57]
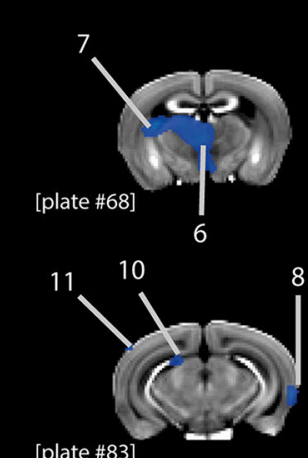

[plate \#83]
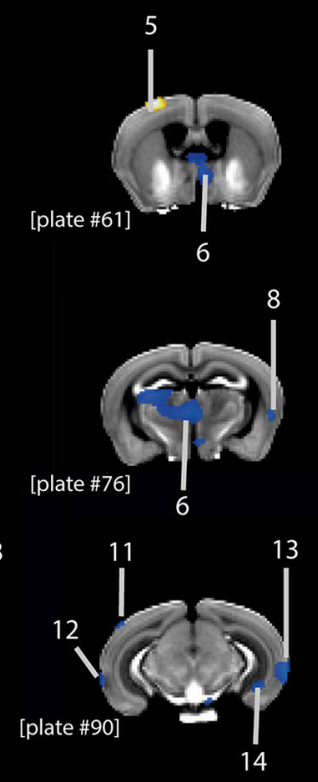

14
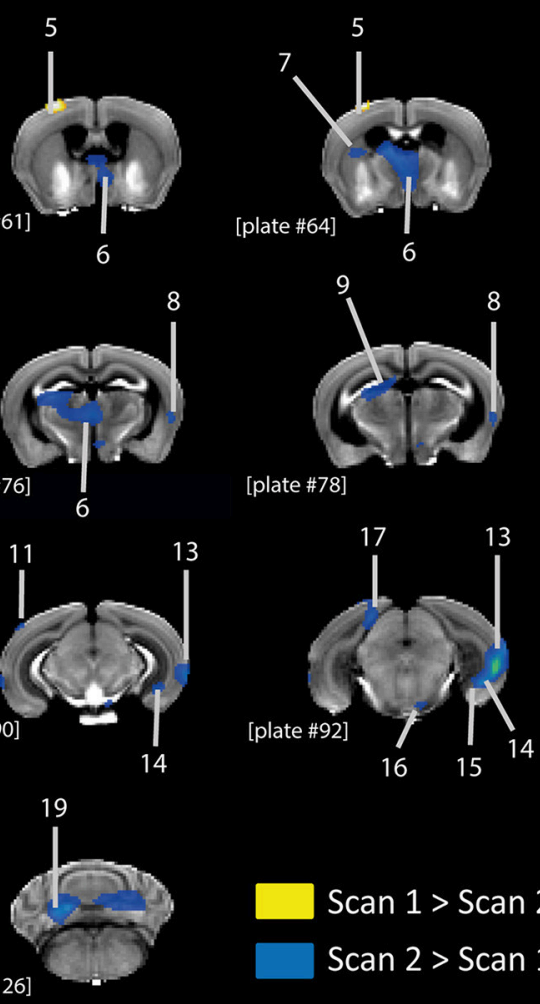

$\operatorname{Scan} 1>\operatorname{Scan} 2$

Scan $2>$ Scan 1

[plate \#111]

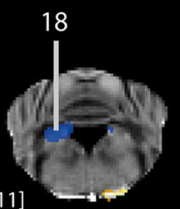

[plate \#126]

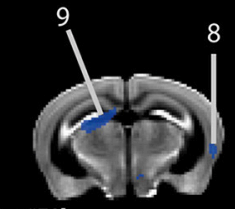


TABLE 1 | List of structures showing differential MEMRI signal between scans 1 and 2, ipsi or contralateral to the reference point (left barrel cortex).

\begin{tabular}{|c|c|c|c|c|c|}
\hline \multirow[b]{2}{*}{ Brain structures } & \multirow[b]{2}{*}{ \# on Figure 1} & \multicolumn{2}{|c|}{ MEMRI signal $\neq$} & \multicolumn{2}{|c|}{ Barrel cortex efferent?* } \\
\hline & & ipsi (L) & contra $(R)$ & ipsi (L) & contra (R) \\
\hline Olfactory bulb-anterior & 1 & & & & \\
\hline Olfactory bulb-posterior & 1 & & & & \\
\hline Orbital area & 2 & & & & \\
\hline Islands of Calleja (striatum) & 3 & & & & \\
\hline Supplemental somatosensory area & 4 & & & & \\
\hline BARREL CORTEX & 5 & & & & \\
\hline Medial thalamic nuclei-anterior & 6 & & & & \\
\hline Medial thalamic nuclei-posterior & 6 & & & & \\
\hline Caudoputamen & 7 & & & & \\
\hline Temporal association areas & 8 & & & & \\
\hline Lateral posterior nucleus of the thalamus & 6 & & & & \\
\hline Dorsal part of the lateral geniculate complex & 6 & & & & \\
\hline Parafascicular nucleus & 6 & & & & \\
\hline Posterior complex of the thalamus & 6 & & & & \\
\hline Anterior pretectal nucleus & 9 & & & & \\
\hline Lateral posterior nucleus of the thalamus & 6 & & & & \\
\hline Nucleus of the optic tract & 10 & & & & \\
\hline Anterolateral visual area & 11 & & & & \\
\hline Perirhinal area & 12 & & & & \\
\hline Ectorhinal area & 13 & & & & \\
\hline Subiculum - ventral part & 14 & & & & \\
\hline Dentate gyrus - ventral part & 15 & & & & \\
\hline Pontine nuclei & 16 & & & & \\
\hline Retrosplenial area & 17 & & & & \\
\hline Superior vestibular nucleus (medulla) & 18 & & & & \\
\hline Cerebellum & 19 & & & & \\
\hline
\end{tabular}

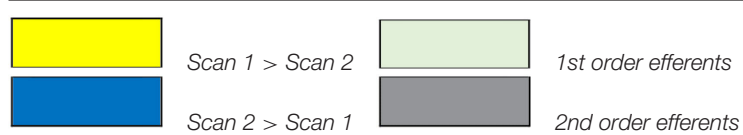

*based on the following references: White and DeAmicis, 1977; Ohara et al., 1980; Montero and Scott, 1981; Ohara and Lieberman, 1981, 1985; Hoogland et al., 1987, 1991; Cornwall and Phillipson, 1988; Welker et al., 1988; Chen et al., 1992; Raos and Bentivoglio, 1993; Bourassa et al., 1995; Hazrati et al., 1995; Pinault et al., 1995; Pinault and Deschenes, 1998; Veinante et al., 2000; Wright et al., 2000; Wang et al., 2005; Aronoff et al., 2010; Zakiewicz et al., 2014; Tang et al., 2016; Guo et al., 2017; Sumser et al., 2017. 
local increases of $\mathrm{Mn}^{2+}$ accumulation in the second scan (scan $2>$ scan 1) were only assessed qualitatively at an uncorrected threshold of $p<0.05$ (cluster extent 20).

Voxel-wise analysis of the MR images was performed in SPM8 (www.fil.ion.ucl.ac.uk/spm). Graphics of activation maps have been created in MRICro (www.cabiatl.com/mricro). All images were ultimately arranged in Adobe Illustrator 10.0.3 (Adobe Systems Inc., NY, USA).

\section{RESULTS}

After correcting for the unspecific global decrease of $\mathrm{Mn}^{2+}$ between the experimental time points, we identified only a single cluster showing higher $\mathrm{Mn}^{2+}$ intensity in the first scan compared to the second ( $\operatorname{scan} 1>\operatorname{scan} 2$ ). This cluster was located in the left barrel cortex $\left(p_{F W E, c l u s t e r}=0.009\right.$, cluster extent 236 voxel), representing activity of the untrimmed whiskers (Figure 1B; Table 1).

In the inverse contrast (scan $2>\operatorname{scan} 1$ ), a number of brain structures could be detected to show a stronger intensity at time point 2 (Figure 1B; Table 1), mainly located in the left hemisphere.

The higher signal in the left barrel cortex (corresponding to the untrimmed whiskers) in scan 1 compared to scan 2 , and the lack of difference in the right barrel cortex (corresponding to the trimmed whiskers) suggests that the sensory blockage by whisker trimming attenuated the $\mathrm{Mn}^{2+}$ transport to projection terminals. This hypothesis is further supported by the clusters showing higher $\mathrm{Mn}^{2+}$ intensity in the second measurement compared to the first (scan $2>$ scan 1 ), which include a large number $(85 \%$ of total) of efferents of the left barrel cortex (Table 1). Therefore, we conclude that $\mathrm{Mn}^{2+}$ is transported from the uptake site to its projection terminals, in an activity-dependent manner.

\section{DISCUSSION}

Here we show that, after systemic $\mathrm{MnCl}_{2}$ injections, both intraand interneuronal transport of $\mathrm{Mn}^{2+}$ is accelerated by the continuous activity of the afferent cells in the brain, when compared to a unilaterally sensory deprived pathway. This conclusion was based on the following observations: (i) only the barrel cortex of the corresponding untrimmed whiskers showed higher MEMRI signal in scan 1 compared to scan 2; (ii) most of the structures that showed higher MEMRI signal in scan 2 compared to scan 1 are efferent to the barrel cortex (Table 1; Figure 2).

\section{The Whisker-Barrel Cortex System}

The mouse barrel-cortex system was chosen as a model due to its well characterized connectivity (Woolsey and Van der Loos, 1970; Welker, 1976) and because of its property of strong and defined neuronal activation in the barrel cortex contralateral to its specific sensory input (Woolsey and Van der Loos, 1970; Axelrad et al., 1976; Peron et al., 2015). Therefore, it is the perfect model system to study changes in neuronal activity due to sensory stimulation or deprivation, and the underlying $\mathrm{Mn}^{2+}$ dynamics related to neuronal activation. This pathway was already used elsewhere to map tactile sense-evoked activity with MEMRI (Weng et al., 2007), BOLD (Lu et al., 2004; de Celis Alonso et al., 2012) and CBV fMRI (Lu et al., 2004) after mechanical whisker stimulation in rats; also with MEMRI after blood-brain barrier ultrasonic disruption and mechanical whisker stimulation in mice (Howles et al., 2010).

For the sake of simplicity, in our conclusion scheme (Figure 2) we represented neurons of the barrel cortex as cell 1 (reference point). These neurons are the cortical representation of a mouse's contralateral whiskers (Woolsey and Van der Loos, 1970; Ferezou et al., 2006). However, it is worth highlighting that after stimulation of the whiskers, sensory information is initially processed by the trigeminal nuclei of the brainstem, followed, in parallel, by the ventroposterior medial (VPM)-lemniscal and extralemniscal pathways-and the posterior medial (POm) nuclei of the thalamus_-paralemniscal pathway_-before reaching the barrel cortex (for review Petersen, 2007; Diamond et al., 2008). Therefore, the barrel cortex cells are already downstream to other brain structures which may take up $\mathrm{Mn}^{2+}$ in an activitydependent manner.

Most of the brain structures which showed higher $\mathrm{Mn}^{2+}$ levels in scan 2 compared to scan 1 turned out to be efferent to the left barrel cortex, including monosynaptic (1st order) and polysynaptic (2nd order) projection sites (Table 1). This connectivity analysis and assignment was made taking the vast barrel cortex connectivity data in the literature into account (for examples see Aronoff et al., 2010; Zakiewicz et al., 2014). Second order efferents were here defined as the projections from either of the two main outputs of the barrel cortex, namely: the thalamic reticular nucleus and the posterior complex of the thalamus (Hoogland et al., 1987; Wright et al., 2000). Some brain structures, especially medial thalamic nuclei, are both 1 st and 2 nd order efferents. In these cases, they were just assigned as 1 st order efferents.

An important point to mention is that most of the whiskerbarrel connectivity literature is based on rat experiments. Large part of this data (Ohara et al., 1980; Montero and Scott, 1981; Ohara and Lieberman, 1981, 1985; Cornwall and Phillipson, 1988; Chen et al., 1992; Raos and Bentivoglio, 1993; Bourassa et al., 1995; Hazrati et al., 1995; Pinault et al., 1995; Pinault and Deschenes, 1998; Veinante et al., 2000; Wright et al., 2000; Wang et al., 2005; Zakiewicz et al., 2014) was included in our analysis to assign structures as barrel cortex efferents. Given the similarities of the rat and mouse nervous system, we do not believe that inter-species differences could falsely or significantly impact the connectivity analysis presented here. However, we acknowledge that small differences between the barrel system connectivity of these species were already reported (Kichula and Huntley, 2008).

The results shown here included most, but not all the barrel cortex efferents previously described. In fact, some of its main outputs, such as the motor cortex or the thalamic reticular nucleus, did not show a differential MEMRI signal in scan 2 compared to scan 1. This might be ascribed to the fact that $\mathrm{Mn}^{2+}$ can be transsynapticaly transported, as already reported elsewhere (Saleem et al., 2002; Pautler et al., 2003; Murayama et al., 2006; Bearer et al., 2007), and also shown here by the geniculate and parafascicular nuclei of the thalamus, which 


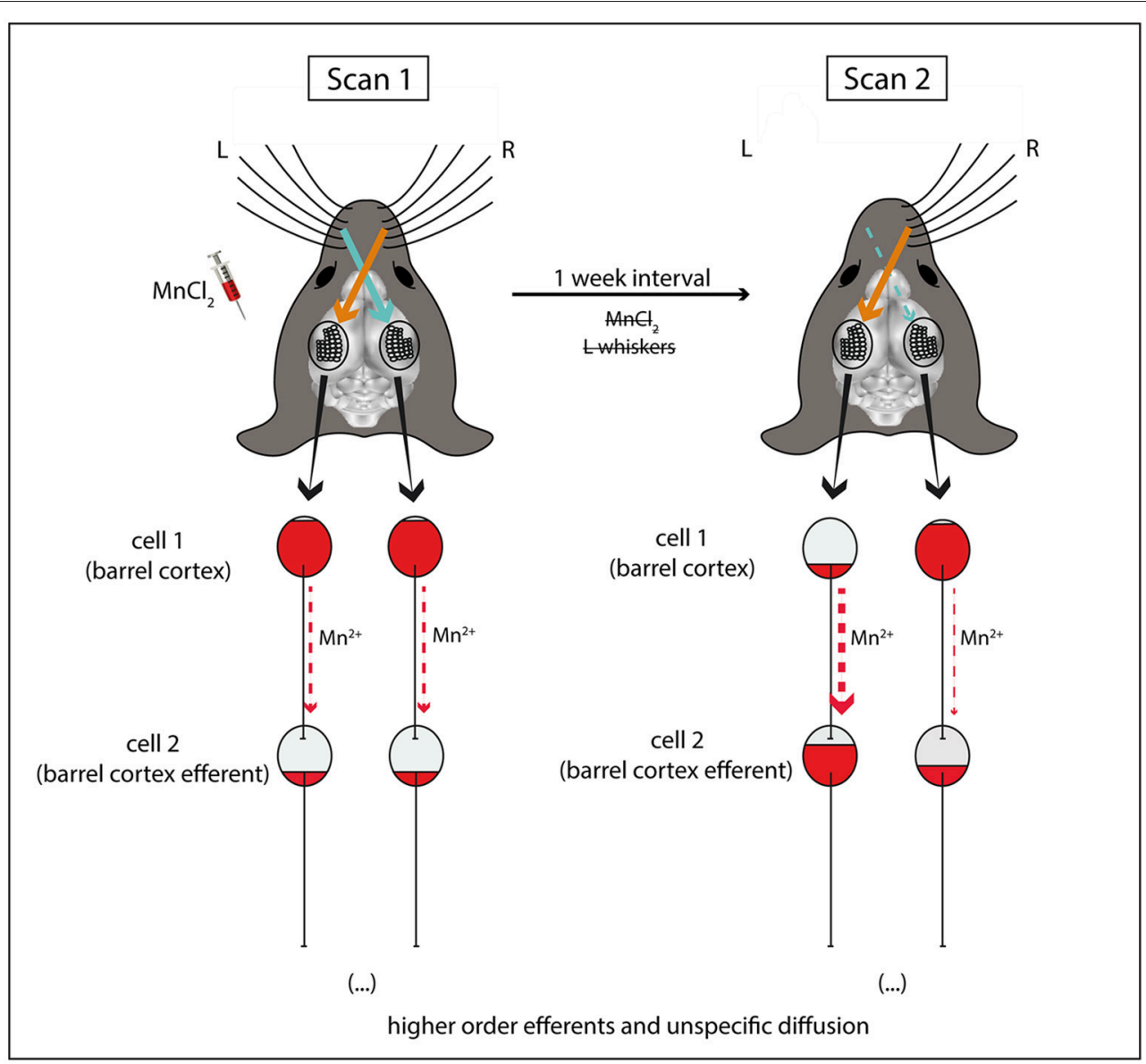

FIGURE 2 | Schematic explanation for the differences in $\mathrm{Mn}^{2+}$ accumulation observed after unilateral sensory deprivation. In the end of sensory enriched housing with intact whiskers and repeated $\mathrm{MnCl}_{2}$ injections, MEMRI (scan 1) reveals equal bilateral accumulation of $\mathrm{Mn}^{2+}$ in the barrel cortices. 1 week later (scan 2) after unilateral sensory deprivation (left side), $\mathrm{Mn}^{2+}$ is cleared from the left but not right barrel cortex (cell 1), due to ongoing sensory inputs from the intact whiskers of the contralateral right side. At the same time, $\mathrm{Mn}^{2+}$ is accumulated in efferent brain structures downstream to the left barrel cortex (cell 2) following activity-dependent axonal/transsynaptic transport. For simplicity reasons, this scheme does not depict the afferences from brain stem structures and the thalamus which relay sensory information from the whiskers to the barrel cortex.

represent 2nd order efferents from the barrel cortex and 1st order efferents from the reticular nucleus. This might lead to an additional dilution of the $\mathrm{Mn}^{2+}$ contrast, hindering its detection by voxel wise brain analysis. Another possibility is that the MEMRI signal might have been filtered out in large structures which receive diffused rather than focused projections, such as the motor cortex, because the signal intensity tends to be higher in compact and densely connected structures (Aoki et al., 2004; Bedenk et al., 2018).

It is important to note that our protocol of partial sensory deprivation (whisker trimming) was applied to adult mice only (3-4 months old) and did not include follicle removal or cauterization. Moreover, considering the short duration of the deprivation (7 days), we do not believe that the results of this study are a consequence of cortical map plasticity, widely described in neurodevelopmental and plasticity studies using the barrel-cortex system model (Van der Loos and Woolsey, 1973; Woolsey and Wann, 1976; Levin and Dunn-Meynell, 1991; Dunn-Meynell et al., 1992; Siucinska and Kossut, 1994; Melzer and Smith, 1996; Kossut and Juliano, 1999; Fox, 2002; Allen et al., 2003; Rema et al., 2003; Schierloh et al., 2003; Shepherd et al., 2003; Dubroff et al., 2005; Fox and Wong, 2005; Shoykhet et al., 2005; Frostig, 2006; Lee et al., 2007; Schubert et al., 2007; Drew and Feldman, 2009; Wu et al., 2011; Gainey et al., 2016; Jacob et al., 2017).

\section{$\mathrm{Mn}^{2+}$ Administration, Toxicity, and Decay}

MEMRI studies have already employed different routes for $\mathrm{Mn}^{2+}$ administration, such as intracerebral injections (Pautler et al., 2003; Watanabe et al., 2004; Yang et al., 2011), intranasal aerosols (Henriksson et al., 1999; Pautler and Koretsky, 2002; Lehallier et al., 2012), intravitreal injection (Pautler et al., 1998; Bearer et al., 2007; Luo et al., 2012), and topic eye application (Lin et al., 2014). These methods are however invasive and often toxic (Bearer et al., 2007; Luo et al., 2012; Lin et al., 2014). Systemic injections have a reduced risk of toxicity if fractionated (Grünecker et al., 2010), or continuously delivered with osmotic mini pumps (Sepulveda et al., 2012; Poole et al., 2017). The 
delayed and limited diffusion of $\mathrm{Mn}^{2+}$ to the brain should also be considered. In each case, care must be taken to find an optimal balance between a sufficient dose to reach the best contrast while minimizing the potential side/toxic effects of $\mathrm{Mn}^{2+}$ in the brain. The use of systemic methods for delivering of $\mathrm{MnCl}_{2}$ has clear advantages, e.g., in case of prolonged behavioral procedures. In some cases, however, systemic treatment has to be combined with the disruption of the blood-brain barrier (BBB), e.g., by mannitol injection (Lin and Koretsky, 1997; Aoki et al., 2002) or by ultrasound (Howles et al., 2010), in order to allow the $\mathrm{Mn}^{2+}$ to quickly reach the brain. In these cases, a single $\mathrm{MnCl}_{2}$ spike injection can be applied. Even with the use of relatively small doses for a single shot that did not cause major apparent side/toxic effects, small impairments as transient motor deficit in skilled reaching, rears, and activity was already described in rats (Alaverdashvili et al., 2017). This limitation should be considered, especially when designing studies with behavioral experiments where fine motor skills are necessary. For longer term investigations (from many hours to days) the disruption of the BBB is not necessary (Yu et al., 2005; Kuo et al., 2006), given that $\mathrm{Mn}^{2+}$ can reach the brain and accumulate in a activitydependent manner in the structures related to the challenge/task performed at least few hours before. This applies in particular to the paradigm used here, where we "pre-loaded" the cells with $\mathrm{Mn}^{2+}$ before the experimental intervention (whiskers trimming). Our data suggest this procedure might also be used for acute behavioral challenges where mice could be first treated with $\mathrm{MnCl}_{2}$ to reach sufficient contrast, followed by repeated scanning before and after the challenge.

One should also not overlook clearance of $\mathrm{Mn}^{2+}$ in the brain when scans are performed long (more than $24 \mathrm{~h}$ ) after the $\mathrm{MnCl}_{2}$ injections have stopped. We previously reported that the half-life of $\mathrm{Mn}^{2+}$, after an $8 \times 30 \mathrm{mg} / \mathrm{kg} \mathrm{MnCl}_{2}$ injection protocol, is about 5-7 days, depending on the brain structures (Grünecker et al., 2013). This point was taken into consideration in our analysis comparing scans 1 and 2, which were performed 1 week apart.

\section{The Interplay of Neuronal Activity and $\mathrm{Mn}^{2+}$ Axonal and Transsynaptic Transport}

Previous studies already investigated the possible role of neuronal activity in $\mathrm{Mn}^{2+}$ axonal and transsynaptic transport in specific pathways with different protocols and obtained, somewhat, contradicting results. For instance, it was shown that $\mathrm{Mn}^{2+}$ is co-released with neurotransmitters after stimulation with high $\mathrm{K}^{+}$(Takeda et al., 1998), indicating that $\mathrm{Mn}^{2+}$ transport is dynamically linked to neural signaling. Later, many groups mapped sensory system activation in response to specific odors (Pautler et al., 1998; Pautler and Koretsky, 2002; Chuang et al., 2009; Lehallier et al., 2012), visual (Bissig and Berkowitz, 2009), or acoustic stimulation (Yu et al., 2005), supporting the idea that $\mathrm{Mn}^{2+}$ transport is activity-dependent. One of these studies (Bearer et al., 2007) employed transgenic blind mice to investigate activity-dependency in $\mathrm{Mn}^{2+}$ dynamics after intravitreal $\mathrm{MnCl}_{2}$ injection and concluded that " $\mathrm{Mn}^{2+}$ is not transmitted efficiently across synapses in the absence of electrical activity in this system," whereas uptake and axonal transport remained intact. This last conclusion is supported by the results of Lowe et al. (2008) showing no difference in MEMRI signal intensity in the visual system between groups treated with $\mathrm{MnCl}_{2}$ only or in combination with cell activity blockers (APB or TTX). On the other hand, accelerated $\mathrm{Mn}^{2+}$ transport after $\mathrm{MnCl}_{2}$ co-treatment with AMPA was already described (Wang et al., 2015), indicating that axonal transport of $\mathrm{Mn}^{2+}$ is dynamically modulated by neuronal activity. In fact, pharmacological blockage of calcium channels also blocked this accelerated transport (Wang et al., 2015). Using the song control system in song birds as a model of neuronal plasticity (for review see Van der Linden et al., 2004), Tindemans et al. (2003) were able to show an activity dependent transsynaptic transport of $\mathrm{Mn}^{2+}$ from the site of local cerebral injection of $\mathrm{Mn}^{2+}$ in the HVC (high vocal center; a relay region of the song control system) to more downstream regions [such as the nucleus robustus arcopallialis (RA) and the striatal area X]. Using dynamic MEMRI, the authors reported that both regions showed a more rapid accumulation of $\mathrm{Mn}^{2+}$ in the stimulated birds. After about $10 \mathrm{~h}$, this difference to non-stimulated birds vanished only for RA, but not for area $\mathrm{X}$, suggesting a differential functional connectivity of the two regions in the song circuitry. Considering these previous reports and the results presented here, we conclude that, even in the case of systemic $\mathrm{MnCl}_{2}$ injection, axonal and transsynaptic transport of $\mathrm{Mn}^{2+}$ is modulated by the activity state of the neuronal pathway. Our results further suggest that reduced neuronal activity due to blockage of sensory inputs attenuates the transport of $\mathrm{Mn}^{2+}$ from its initial accumulation site, while continuous neuronal activity promotes the transport of $\mathrm{Mn}^{2+}$ between neurons.

\section{Ketamine and NMDA Receptor Blockage}

We used ketamine in an anesthetic dose $(138 \mathrm{mg} / \mathrm{kg}$ ) (Buitrago et al., 2008) in order to block NMDA receptor-related neuronal activity (Anis et al., 1983) and, thus, to avoid further entrance of $\mathrm{Mn}^{2+}$ in neurons (Itoh et al., 2008), which might be caused by transportation of the animals from the vivarium to the scanning room and/or their fixation inside the scanner. We are aware of the fact that ketamine has complex and not fully understood mechanisms of action and might lead to unspecific effects which are unrelated to anesthesia such as hyperlocomotion (Hayase et al., 2006) or antidepressant-like effects in low doses (Kavalali and Monteggia, 2012). However, in the present study we can exclude that ketamine has affected MEMRI signal intensities by itself, due to: (i) $\mathrm{MnCl}_{2}$ treatment was given chronically for 8 days and finished at least $12 \mathrm{~h}$ before ketamine injection; (ii) there was only a short interval $(\sim 30 \mathrm{~min})$ between ketamine administration and the scanning procedure; and (iii) the withinsubject design used here (ketamine treatment before both first and second scans).

\section{CONCLUSION}

Taken together, we provide evidence for neuronal activitydependent accelerated transport of $\mathrm{Mn}^{2+}$ to projection terminals and across synapses. This observation allows for a more careful design of the experiments using systemic $\mathrm{MnCl}_{2}$ treatment. At the same time, it adds another layer of components to the interpretation of the results obtained by MEMRI. 


\section{AUTHOR CONTRIBUTIONS}

SA-C and CW designed the study; SA-C performed the experiments and wrote the first draft of the manuscript; $M C$ analyzed the data. All the authors discussed the results and approved the final manuscript.

\section{FUNDING}

This work was funded by the Max Planck Society, by a grant from the German-Israeli Foundation for Scientific Research and

\section{REFERENCES}

Alaverdashvili, M., Lapointe, V., Whishaw, I. Q., and Cross, A. R. (2017). Manganese-enhanced magnetic resonance imaging and studies of rat behavior: transient motor deficit in skilled reaching, rears, and activity in rats after a single dose of MnCl2. Magn. Reson. Insights 10, 1178623-17706878. doi: $10.1177 / 1178623 \mathrm{X} 17706878$

Allen, C. B., Celikel, T., and Feldman, D. E. (2003). Long-term depression induced by sensory deprivation during cortical map plasticity in vivo. Nat. Neurosci. 6, 291-299. doi: 10.1038/nn1012

Anis, N. A., Berry, S. C., Burton, N. R., and Lodge, D. (1983). The dissociative anaesthetics, ketamine and phencyclidine, selectively reduce excitation of central mammalian neurones by N-methyl-aspartate. Br. J. Pharmacol. 79, 565-575. doi: 10.1111/j.1476-5381.1983.tb11031.x

Aoki, I., Tanaka, C., Takegami, T., Ebisu, T., Umeda, M., Fukunaga, M., et al. (2002). Dynamic activity-induced manganese-dependent contrast magnetic resonance imaging (DAIM MRI). Magn. Reson. Med. 48, 927-933. doi: $10.1002 / \mathrm{mrm} .10320$

Aoki, I., Wu, Y. J., Silva, A. C., Lynch, R. M., and Koretsky, A. P. (2004). In vivo detection of neuroarchitecture in the rodent brain using manganese-enhanced MRI. Neuroimage 22, 1046-1059. doi: 10.1016/j.neuroimage.2004.03.031

Aronoff, R., Matyas, F., Mateo, C., Ciron, C., Schneider, B., and Petersen, C. C. (2010). Long-range connectivity of mouse primary somatosensory barrel cortex. Eur. J. Neurosci. 31, 2221-2233. doi: 10.1111/j.1460-9568.2010.07264.x

Arvidson, B. (1977). Retrograde axonal transport of horseradish peroxidase from cornea to trigeminal ganglion. Acta Neuropathol. 38, 49-52. doi: $10.1007 / \mathrm{BF} 00691276$

Axelrad, H., Verley, R., and Farkas, E. (1976). Responses evoked in mouse and rat SI cortex by vibrissa stimulation. Neurosci. Lett. 3, 265-274. doi: 10.1016/0304-3940(76)90053-7

Bangasser, D. A., Lee, C. S., Cook, P. A., Gee, J. C., Bhatnagar, S., and Valentino, R. J. (2013). Manganese-enhanced magnetic resonance imaging (MEMRI) reveals brain circuitry involved in responding to an acute novel stress in rats with a history of repeated social stress. Physiol. Behav. 122, 228-236. doi: 10.1016/j.physbeh.2013.04.008

Bearer, E. L., Falzone, T. L., Zhang, X., Biris, O., Rasin, A., and Jacobs, R. E. (2007). Role of neuronal activity and kinesin on tract tracing by manganese-enhanced MRI (MEMRI). Neuroimage (37 Suppl. 1), S37-S46. doi: 10.1016/j.neuroimage.2007.04.053

Bedenk, B. T., Almeida-Corrêa, S., Jurik, A., Dedic, N., Grünecker, B., Genewsky, A. J., et al. (2018). Mn2+ dynamics in manganese-enhanced MRI (MEMRI): Cav1.2 channel-mediated uptake and preferential accumulation in projection terminals. Neuroimage 169, 374-382. doi: 10.1016/j.neuroimage.2017. 12.054

Bissig, D., and Berkowitz, B. A. (2009). Manganese-enhanced MRI of layer-specific activity in the visual cortex from awake and free-moving rats. Neuroimage 44, 627-635. doi: 10.1016/j.neuroimage.2008.10.013

Bourassa, J., Pinault, D., and Deschênes, M. (1995). Corticothalamic projections from the cortical barrel field to the somatosensory thalamus in rats: a singlefibre study using biocytin as an anterograde tracer. Eur. J. Neurosci. 7, 19-30. doi: 10.1111/j.1460-9568.1995.tb01016.x
Development (GIF 1-270-421.10-2016) to CW and by a $\mathrm{PhD}$ stipend from CAPES (Brazil; BEX 9694/13-7) to SA-C.

\section{ACKNOWLEDGMENTS}

The authors would like to thank Dr. Elmira Anderzhanova, Julia Sulger, and Daniel Heinz from the Max Planck Institute of Psychiatry for their assistance with the graphical work, and Dr. Alec Dick from the Max Planck Institute of Psychiatry for proof-reading and English editing the manuscript.

Buitrago, S., Martin, T. E., Tetens-Woodring, J., Belicha-Villanueva, A., and Wilding, G. E. (2008). Safety and efficacy of various combinations of injectable anesthetics in BALB/c mice. J. Am. Assoc. Lab. Anim. Sci. 47, 11-17.

Chen, K. H., Chen, D. Y., and Liang, K. C. (2013). Functional connectivity changes during consolidation of inhibitory avoidance memory in rats: a manganese-enhanced MRI study. Chin. J. Physiol. 56, 269-281. doi: 10.4077/CJP.2013.BAB144

Chen, S., Raos, V., and Bentivoglio, M. (1992). Connections of the thalamic reticular nucleus with the contralateral thalamus in the rat. Neurosci. Lett. 147, 85-88. doi: 10.1016/0304-3940(92)90780-B

Chen, W., Tenney, J., Kulkarni, P., and King, J. A. (2007). Imaging unconditioned fear response with manganese-enhanced MRI (MEMRI). Neuroimage 37, 221-229. doi: 10.1016/j.neuroimage.2007.05.001

Chmielowska, J., Carvell, G. E., and Simons, D. J. (1989). Spatial organization of thalamocortical and corticothalamic projection systems in the rat SmI barrel cortex. J. Comp. Neurol. 285, 325-338. doi: 10.1002/cne.902850304

Chuang, K. H., Lee, J. H., Silva, A. C., Belluscio, L., and Koretsky, A. P. (2009). Manganese enhanced MRI reveals functional circuitry in response to odorant stimuli. Neuroimage 44, 363-372. doi: 10.1016/j.neuroimage.2008.08.046

Chung, K., Wallace, J., Kim, S.-Y., Kalyanasundaram, S., Andalman, A. S., Davidson, T. J., et al. (2013). Structural and molecular interrogation of intact biological systems. Nature 497, 332-337. doi: 10.1038/nature12107

Cornwall, J., and Phillipson, O. T. (1988). Afferent projections to the parafascicular thalamic nucleus of the rat, as shown by the retrograde transport of wheat germ agglutinin. Brain Res. Bull. 20, 139-150. doi: 10.1016/0361-9230(88)90171-2

de Celis Alonso, B., Sergeyeva, M., Brune, K., and Hess, A. (2012). Lateralization of responses to vibrissal stimulation: connectivity and information integration in the rat sensory-motor cortex assessed with fMRI. Neuroimage 62, 2101-2109. doi: 10.1016/j.neuroimage.2012.05.045

Diamond, M. E., von Heimendahl, M., Knutsen, P. M., Kleinfeld, D., and Ahissar, E. (2008). 'Where' and 'what' in the whisker sensorimotor system. Nat. Rev. Neurosci. 9, 601-612. doi: 10.1038/nrn2411

Drapeau, P., and Nachshen, D. A. (1984). Manganese fluxes and manganesedependent neurotransmitter release in presynaptic nerve endings isolated from rat brain. J. Physiol. 348, 493-510. doi: 10.1113/jphysiol.1984.sp015121

Drew, P. J., and Feldman, D. E. (2009). Intrinsic signal imaging of deprivationinduced contraction of whisker representations in rat somatosensory cortex. Cereb. Cortex 19, 331-348. doi: 10.1093/cercor/bhn085

Dubroff, J. G., Stevens, R. T., Hitt, J., Maier, D. L., McCasland, J. S., and Hodge, C. J. (2005). Use-dependent plasticity in barrel cortex: intrinsic signal imaging reveals functional expansion of spared whisker representation into adjacent deprived columns. Somatosens. Mot. Res. 22, 25-35. doi: 10.1080/08990220500084990

Dunn-Meynell, A. A., Benowitz, L. I., and Levin, B. E. (1992). Vibrissectomy induced changes in GAP-43 immunoreactivity in the adult rat barrel cortex. J. Comp. Neurol. 315, 160-170. doi: 10.1002/cne.903150204

Eschenko, O., Canals, S., Simanova, I., Beyerlein, M., Murayama, Y., and Logothetis, N. K. (2010). Mapping of functional brain activity in freely behaving rats during voluntary running using manganese-enhanced MRI: implication for longitudinal studies. Neuroimage 49, 2544-2555. doi: 10.1016/j.neuroimage.2009.10.079 
Ferezou, I., Bolea, S., and Petersen, C. C. (2006). Visualizing the cortical representation of whisker touch: voltage-sensitive dye imaging in freely moving mice. Neuron 50, 617-629. doi: 10.1016/j.neuron.2006.03.043

Fox, K. (2002). Anatomical pathways and molecular mechanisms for plasticity in the barrel cortex. Neuroscience 111, 799-814. doi: 10.1016/S0306-4522(02)00027-1

Fox, K., and Wong, R. O. (2005). A comparison of experience-dependent plasticity in the visual and somatosensory systems. Neuron 48, 465-477. doi: 10.1016/j.neuron.2005.10.013

Franklin, K. B. J., and Paxinos, G. (2007). The Mouse Brain in Stereotaxic Coordinates, 3rd Edn. San Diego, CA: Academic Press; Elsevier.

Frostig, R. D. (2006). Functional organization and plasticity in the adult rat barrel cortex: moving out-of-the-box. Curr. Opin. Neurobiol. 16, 445-450. doi: 10.1016/j.conb.2006.06.001

Gainey, M. A., Wolfe, R., Pourzia, O., and Feldman, D. E. (2016). Whisker deprivation drives two phases of inhibitory synapse weakening in layer 4 of rat somatosensory cortex. PLoS ONE 11:e0148227. doi: 10.1371/journal.pone.0148227

Gavin, C. E., Gunter, K. K., and Gunter, T. E. (1990). Manganese and calcium efflux kinetics in brain mitochondria. Relevance to manganese toxicity. Biochem. J. 266, 329-334. doi: 10.1042/bj2660329

Gerfen, C. R., and Sawchenko, P. E. (1984). An anterograde neuroanatomical tracing method that shows the detailed morphology of neurons, their axons and terminals: immunohistochemical localization of an axonally transported plant lectin, Phaseolus vulgaris leucoagglutinin (PHA-L). Brain Res. 290, 219-238. doi: 10.1016/0006-8993(84)90 940-5

Grünecker, B., Kaltwasser Sebastian, F., Peterse, Y., Sämann Philipp, G., Schmidt Mathias, V., Wotjak Carsten, T., et al. (2010). Fractionated manganese injections: effects on MRI contrast enhancement and physiological measures in C57BL/6 mice. NMR Biomed. 23, 913-921. doi: 10.1002/nbm.1508

Grünecker, B., Kaltwasser, S. F., Zappe, A. C., Bedenk, B. T., Bicker, Y., Spoormaker, V. I., et al. (2013). Regional specificity of manganese accumulation and clearance in the mouse brain: implications for manganese-enhanced MRI. NMR Biomed. 26, 542-556. doi: 10.1002/nbm.2891

Guo, C., Peng, J., Zhang, Y., Li, A., Li, Y., Yuan, J., et al. (2017). Single-axon level morphological analysis of corticofugal projection neurons in mouse barrel field. Sci. Rep. 7:2846. doi: 10.1038/s41598-017-03000-8

Hayase, T., Yamamoto, Y., and Yamamoto, K. (2006). Behavioral effects of ketamine and toxic interactions with psychostimulants. BMC Neurosci. 7:25. doi: 10.1186/1471-2202-7-25

Hazrati, L. N., Pinault, D., and Parent, A. (1995). The thalamic reticular nucleus does not send commissural projection to the contralateral parafascicular nucleus in the rat. Brain Res. 679, 123-134. doi: 10.1016/0006-8993(95)00223-D

Henriksson, J., Tallkvist, J., and Tjälve, H. (1999). Transport of manganese via the olfactory pathway in rats: dosage dependency of the uptake and subcellular distribution of the metal in the olfactory epithelium and the brain. Toxicol. Appl. Pharmacol. 156, 119-128. doi: 10.1006/taap.1999.8639

Hoch, T., Kreitz, S., Gaffling, S., Pischetsrieder, M., and Hess, A. (2013). Manganese-enhanced magnetic resonance imaging for mapping of whole brain activity patterns associated with the intake of snack food in ad libitum fed rats. PLoS ONE 8:e55354. doi: 10.1371/journal.pone.0055354

Hoogland, P. V., Welker, E., and Van der Loos, H. (1987). Organization of the projections from barrel cortex to thalamus in mice studied with Phaseolus vulgaris-leucoagglutinin and HRP. Exp. Brain Res. 68, 73-87. doi: 10.1007/BF00255235

Hoogland, P. V., Wouterlood, F. G., Welker, E., and Van der Loos, H. (1991). Ultrastructure of giant and small thalamic terminals of cortical origin: a study of the projections from the barrel cortex in mice using Phaseolus vulgaris leucoagglutinin (PHA-L). Exp. Brain Res. 87, 159-172. doi: 10.1007/BF00228517

Howles, G. P., Qi, Y., and Johnson, G. A. (2010). Ultrasonic disruption of the blood-brain barrier enables in vivo functional mapping of the mouse barrel field cortex with manganese-enhanced MRI. Neuroimage 50, 1464-1471. doi: 10.1016/j.neuroimage.2010.01.050

Huang, C. M., Lee, S. H., Hsiao, I. T., Kuan, W. C., Wai, Y. Y., Ko, H. J., et al. (2010). Study-specific EPI template improves group analysis in functional MRI of young and older adults. J. Neurosci. Methods 189, 257-266. doi: 10.1016/j.jneumeth.2010.03.021
Itoh, K., Sakata, M., Watanabe, M., Aikawa, Y., and Fujii, H. (2008). The entry of manganese ions into the brain is accelerated by the activation of N-methyl-d-aspartate receptors. Neuroscience 154, 732-740. doi: 10.1016/j.neuroscience.2008.03.080

Jacob, V., Mitani, A., Toyoizumi, T., and Fox, K. (2017). Whisker row deprivation affects the flow of sensory information through rat barrel cortex. J. Neurophysiol. 117, 4-17. doi: 10.1152/jn.00289.2016

Kavalali, E. T., and Monteggia, L. M. (2012). Synaptic mechanisms underlying rapid antidepressant action of ketamine. Am. J. Psychiatry 169, 1150-1156. doi: 10.1176/appi.ajp.2012.12040531

Kichula, E. A., and Huntley, G. W. (2008). Developmental and comparative aspects of posterior medial thalamocortical innervation of the barrel cortex in mice and rats. J. Comp. Neurol. 509, 239-258. doi: 10.1002/cne.21690

Kossut, M., and Juliano, S. L. (1999). Anatomical correlates of representational map reorganization induced by partial vibrissectomy in the barrel cortex of adult mice. Neuroscience 92, 807-817. doi: 10.1016/S0306-4522(98)00722-2

Kuo, Y. T., Herlihy, A. H., So, P. W., and Bell, J. D. (2006). Manganese-enhanced magnetic resonance imaging (MEMRI) without compromise of the bloodbrain barrier detects hypothalamic neuronal activity in vivo. NMR Biomed. 19, 1028-1034. doi: $10.1002 / \mathrm{nbm} .1070$

Laine, M. A., Sokolowska, E., Dudek, M., Callan, S. A., Hyytia, P., and Hovatta, I. (2017). Brain activation induced by chronic psychosocial stress in mice. Sci. Rep. 7:15061. doi: 10.1038/s41598-017-15422-5

Lee, S. H., Land, P. W., and Simons, D. J. (2007). Layer- and cell-type-specific effects of neonatal whisker-trimming in adult rat barrel cortex. J. Neurophysiol. 97, 4380-4385. doi: 10.1152/jn.01217.2006

Lehallier, B., Coureaud, G., Maurin, Y., and Bonny, J. M. (2012). Effects of manganese injected into rat nostrils: implications for in vivo functional study of olfaction using MEMRI. Magn. Reson. Imaging 30, 62-69. doi: 10.1016/j.mri.2011.08.009

Lein, E. S., Hawrylycz, M. J., Ao, N., Ayres, M., Bensinger, A., Bernard, A., et al. (2006). Genome-wide atlas of gene expression in the adult mouse brain. Nature 445, 168-176. doi: 10.1038/nature 05453

Levin, B. E., and Dunn-Meynell, A. (1991). Adult rat barrel cortex plasticity occurs at 1 week but not at 1 day after vibrissectomy as demonstrated by the 2-deoxyglucose method. Exp. Neurol. 113, 237-248. doi: 10.1016/0014-4886(91)90180-K

Lin, T. H., Chiang, C. W., Trinkaus, K., Spees, W. M., Sun, P., and Song, S. K. (2014). Manganese-enhanced MRI (MEMRI) via topical loading of $\mathrm{Mn}(2+)$ significantly impairs mouse visual acuity: a comparison with intravitreal injection. NMR Biomed. 27, 390-398. doi: 10.1002/nbm.3073

Lin, Y. J., and Koretsky, A. P. (1997). Manganese ion enhances T1-weighted MRI during brain activation: an approach to direct imaging of brain function. Magn. Reson. Med. 38, 378-388. doi: 10.1002/mrm.1910380305

Lowe, A. S., Thompson, I. D., and Sibson, N. R. (2008). Quantitative manganese tract tracing: dose-dependent and activity-independent terminal labelling in the mouse visual system. NMR Biomed. 21, 859-867. doi: 10.1002/ nbm. 1272

Lu, H., Patel, S., Luo, F., Li, S. J., Hillard, C. J., Ward, B. D., et al. (2004). Spatial correlations of laminar BOLD and CBV responses to rat whisker stimulation with neuronal activity localized by Fos expression. Magn. Reson. Med. 52, 1060-1068. doi: 10.1002/mrm.20265

Luo, L., Xu, H., Li, Y., Du, Z., Sun, X., Ma, Z., et al. (2012). Manganese-enhanced MRI optic nerve tracking: effect of intravitreal manganese dose on retinal toxicity. NMR Biomed. 25, 1360-1368. doi: 10.1002/nbm.2808

Lutkenhoff, E., Karlsgodt, K. H., Gutman, B., Stein, J. L., Thompson, P. M., Cannon, T. D., et al. (2012). Structural and functional neuroimaging phenotypes in dysbindin mutant mice. Neuroimage 62, 120-129. doi: 10.1016/j.neuroimage.2012.05.008

Melzer, P., and Smith, C. B. (1996). Plasticity of metabolic whisker maps in somatosensory brainstem and thalamus of mice with neonatal lesions of whisker follicles. Eur. J. Neurosci. 8, 1853-1864. doi: 10.1111/j.1460-9568.1996.tb01329.x

Milchenko, M. V., Pianykh, O. S., and Tyler, J. M. (2006). The fast automatic algorithm for correction of MR bias field. J. Magn. Reson. Imaging 24, 891-900. doi: 10.1002/jmri.20695

Montero, V. M., and Scott, G. L. (1981). Synaptic terminals in the dorsal lateral geniculate nucleus from neurons of the thalamic reticular nucleus: a light 
and electron microscope autoradiographic study. Neuroscience 6, 2561-2577. doi: 10.1016/0306-4522(81)90102-0

Murayama, Y., Weber, B., Saleem, K. S., Augath, M., and Logothetis, N. K. (2006). Tracing neural circuits in vivo with Mn-enhanced MRI. Magn. Reson. Imaging 24, 349-358. doi: 10.1016/j.mri.2005.12.031

Nordhøy, W., Anthonsen, H. W., Bruvold, M., Brurok, H., Skarra, S., Krane, J., et al. (2004). Intracellular manganese ions provide strong T1 relaxation in rat myocardium. Magn. Reson. Med. 52, 506-514. doi: 10.1002/mrm.20199

Ohara, P. T., and Lieberman, A. R. (1981). Thalamic reticular nucleus: anatomical evidence that cortico-reticular axons establish monosynaptic contact with reticulo-geniculate projection cells. Brain Res. 207, 153-156. doi: 10.1016/0006-8993(81)90685-5

Ohara, P. T., and Lieberman, A. R. (1985). The thalamic reticular nucleus of the adult rat: experimental anatomical studies. J. Neurocytol. 14, 365-411. doi: $10.1007 / \mathrm{BF} 01217752$

Ohara, P. T., Sefton, A. J., and Lieberman, A. R. (1980). Mode of termination of afferents from the thalamic reticular nucleus in the dorsal lateral geniculate nucleus of the rat. Brain Res. 197, 503-506. doi: 10.1016/0006-8993(80)91136-1

Pautler, R. G. (2004). In vivo, trans-synaptic tract-tracing utilizing manganeseenhanced magnetic resonance imaging (MEMRI). NMR Biomed. 17, 595-601. doi: $10.1002 / \mathrm{nbm} .942$

Pautler, R. G., and Koretsky, A. P. (2002). Tracing odor-induced activation in the olfactory bulbs of mice using manganese-enhanced magnetic resonance imaging. Neuroimage 16, 441-448. doi: 10.1006/nimg.2002.1075

Pautler, R. G., Mongeau, R., and Jacobs, R. E. (2003). In vivo trans-synaptic tract tracing from the murine striatum and amygdala utilizing manganese enhanced MRI (MEMRI). Magn. Reson. Med. 50, 33-39. doi: 10.1002/mrm. 10498

Pautler, R. G., Silva, A. C., and Koretsky, A. P. (1998). In vivo neuronal tract tracing using manganese-enhanced magnetic resonance imaging. Magn. Reson. Med. 40, 740-748. doi: 10.1002/mrm.1910400515

Peron, S. P., Freeman, J., Iyer, V., Guo, C., and Svoboda, K. (2015). A Cellular resolution map of barrel cortex activity during tactile behavior. Neuron 86, 783-799. doi: 10.1016/j.neuron.2015.03.027

Petersen, C. C. (2007). The functional organization of the barrel cortex. Neuron 56, 339-355. doi: 10.1016/j.neuron.2007.09.017

Pinault, D., Bourassa, J., and Deschênes, M. (1995). Thalamic reticular input to the rat visual thalamus: a single fiber study using biocytin as an anterograde tracer. Brain Res. 670, 147-152. doi: 10.1016/0006-8993(94)01303-Y

Pinault, D., and Deschênes, M. (1998). Projection and innervation patterns of individual thalamic reticular axons in the thalamus of the adult rat: a three-dimensional, graphic, and morphometric analysis. J. Comp. Neurol. 391, 180-203. doi: 10.1002/(SICI)1096-9861(19980209)391:2\&lt;180::AIDCNE3\&gt; 3.0.CO;2-Z

Poole, D. S., Doorenweerd, N., Plomp, J. J., Mahfouz, A., Reinders, M. J. T., and van der Weerd, L. (2017). Continuous infusion of manganese improves contrast and reduces side effects in manganese-enhanced magnetic resonance imaging studies. Neuroimage 147, 1-9. doi: 10.1016/j.neuroimage.2016.09.030

Quattrochi, J. J., Mamelak, A. N., Madison, R. D., Macklis, J. D., and Hobson, J. A. (1989). Mapping neuronal inputs to REM sleep induction sites with carbacholfluorescent microspheres. Science 245, 984-986. doi: 10.1126/science.2475910

Raos, V., and Bentivoglio, M. (1993). Crosstalk between the two sides of the thalamus through the reticular nucleus: a retrograde and anterograde tracing study in the rat. J. Comp. Neurol. 332, 145-154. doi: 10.1002/cne.903320202

Rema, V., Armstrong-James, M., and Ebner, F. F. (2003). Experiencedependent plasticity is impaired in adult rat barrel cortex after whiskers are unused in early postnatal life. J. Neurosci. 23, 358-366. doi: 10.1523/JNEUROSCI.23-01-00358.2003

Saleem, K. S., Pauls, J. M., Augath, M., Trinath, T., Prause, B. A., Hashikawa, T., et al. (2002). Magnetic resonance imaging of neuronal connections in the macaque monkey. Neuron 34, 685-700. doi: 10.1016/S0896-6273(02)00718-3

Schierloh, A., Eder, M., Zieglgänsberger, W., and Dodt, H. U. (2003). Sensory deprivation changes the pattern of synaptic connectivity in rat barrel cortex. Neuroreport 14, 1787-1791. doi: 10.1097/00001756-200310060-00006

Schmued, L. C., and Fallon, J. H. (1986). Fluoro-Gold: a new fluorescent retrograde axonal tracer with numerous unique properties. Brain Res. 377, 147-154. doi: 10.1016/0006-8993(86)91199-6

Schubert, D., Kötter, R., and Staiger, J. F. (2007). Mapping functional connectivity in barrel-related columns reveals layer- and cell type-specific microcircuits. Brain Struct. Funct. 212, 107-119. doi: 10.1007/s00429-0070147-z

Sepulveda, M. R., Dresselaers, T., Vangheluwe, P., Everaerts, W., Himmelreich, U., Mata, A. M., et al. (2012). Evaluation of manganese uptake and toxicity in mouse brain during continuous $\mathrm{MnCl} 2$ administration using osmotic pumps. Contrast Media Mol. Imaging 7, 426-434. doi: 10.1002/cmmi.1469

Shepherd, G. M., Pologruto, T. A., and Svoboda, K. (2003). Circuit analysis of experience-dependent plasticity in the developing rat barrel cortex. Neuron 38, 277-289. doi: 10.1016/S0896-6273(03)00152-1

Shoykhet, M., Land, P. W., and Simons, D. J. (2005). Whisker trimming begun at birth or on postnatal day 12 affects excitatory and inhibitory receptive fields of layer IV barrel neurons. J. Neurophysiol. 94, 3987-3995. doi: 10.1152/jn.00569.2005

Siucinska, E., and Kossut, M. (1994). Short term changes of cortical body maps following partial vibrissectomy in adult mice. Acta Neurobiol. Exp. 54, 345-354.

Sloot, W. N., and Gramsbergen, J. B. (1994). Axonal transport of manganese and its relevance to selective neurotoxicity in the rat basal ganglia. Brain Res. 657, 124-132. doi: 10.1016/0006-8993(94)90959-8

Spiller, M., Brown, R. D. III, Koenig, S. H., and Wolf, G. L. (1988). Longitudinal proton relaxation rates in rabbit tissues after intravenous injection of free and chelated $\mathrm{Mn}^{2+}$. Magn. Reson. Med. 8, 293-313. doi: 10.1002/mrm. 1910080307

Sumser, A., Mease, R. A., Sakmann, B., and Groh, A. (2017). Organization and somatotopy of corticothalamic projections from L5B in mouse barrel cortex. Proc. Natl. Acad. Sci. U.S.A. 114, 8853-8858. doi: 10.1073/pnas.1704302114

Takeda, A., Kodama, Y., Ishiwatari, S., and Okada, S. (1998). Manganese transport in the neural circuit of rat CNS. Brain Res. Bull. 45, 149-152. doi: 10.1016/S0361-9230(97)00330-4

Tambalo, S., Daducci, A., Fiorini, S., Boschi, F., Mariani, M., Marinone, M., et al. (2009). Experimental protocol for activation-induced manganeseenhanced MRI (AIM-MRI) based on quantitative determination of Mn content in rat brain by fast T1 mapping. Magn. Reson. Med. 62, 1080-1084. doi: 10.1002/mrm.22095

Tang, X., Wu, D., Gu, L. H., Nie, B. B., Qi, X. Y., Wang, Y. J., et al. (2016). Spatial learning and memory impairments are associated with increased neuronal activity in 5XFAD mouse as measured by manganeseenhanced magnetic resonance imaging. Oncotarget 7, 57556-57570. doi: 10.18632 /oncotarget.11353

Tindemans, I., Verhoye, M., Balthazart, J., and Van Der Linden, A. (2003). In vivo dynamic ME-MRI reveals differential functional responses of RA- and area X-projecting neurons in the HVC of canaries exposed to conspecific song. Eur. J. Neurosci. 18, 3352-3360. doi: 10.1111/j.1460-9568.2003. 03056.x

Van der Linden, A., Van Meir, V., Tindemans, I., Verhoye, M., and Balthazart, J. (2004). Applications of manganese-enhanced magnetic resonance imaging (MEMRI) to image brain plasticity in song birds. NMR Biomed. 17, 602-612. doi: $10.1002 / \mathrm{nbm} .936$

Van der Loos, H., and Woolsey, T. A. (1973). Somatosensory cortex: structural alterations following early injury to sense organs. Science 179, 395-398. doi: 10.1126/science. 179.4071 .395

Veenman, C. L., Reiner, A., and Honig, M. G. (1992). Biotinylated dextran amine as an anterograde tracer for single- and double-labeling studies. J. Neurosci. Methods 41, 239-254. doi: 10.1016/0165-0270(92)90089-V

Veinante, P., Lavallée, P., and Deschênes, M. (2000). Corticothalamic projections from layer 5 of the vibrissal barrel cortex in the rat. J. Comp. Neurol. 424, 197-204. doi: 10.1002/1096-9861(20000821)424:2\&lt;197::AIDCNE1\&gt;3.0.CO;2-6

Wang, J., Huo, F. Q., Li, Y. Q., Chen, T., Han, F., and Tang, J. S. (2005). Thalamic nucleus submedius receives GABAergic projection from thalamic reticular nucleus in the rat. Neuroscience 134, 515-523. doi: 10.1016/j.neuroscience.2005.04.025

Wang, L., Lu, H., Brown, P. L., Rea, W., Vaupel, B., Yang, Y., et al. (2015) Manganese-enhanced MRI reflects both activity-independent and activitydependent uptake within the rat habenulomesencephalic pathway. PLOS ONE 10:e0127773. doi: 10.1371/journal.pone. 0127773

Watanabe, T., Radulovic, J., Spiess, J., Natt, O., Boretius, S., Frahm, J. et al. (2004). In vivo 3D MRI staining of the mouse hippocampal system using intracerebral injection of $\mathrm{MnCl} 2$. Neuroimage 22, 860-867. doi: 10.1016/j.neuroimage.2004.01.028 
Welker, C. (1976). Receptive fields of barrels in the somatosensory neocortex of the rat. J. Comp. Neurol. 166, 173-189. doi: 10.1002/cne.901660205

Welker, E., Hoogland, P. V., and Van der Loos, H. (1988). Organization of feedback and feedforward projections of the barrel cortex: a PHA-L study in the mouse. Exp. Brain Res. 73, 411-435. doi: 10.1007/BF00248234

Weng, J. C., Chen, J. H., Yang, P. F., and Tseng, W. Y. (2007). Functional mapping of rat barrel activation following whisker stimulation using activity-induced manganese-dependent contrast. Neuroimage 36, 1179-1188. doi: 10.1016/j.neuroimage.2007.04.010

White, E. L., and DeAmicis, R. A. (1977). Afferent and efferent projections of the region in mouse $\mathrm{SmL}$ cortex which contains the posteromedial barrel subfield. J. Comp. Neurol. 175, 455-482. doi: 10.1002/cne.901750405

Wickersham, I. R., Finke, S., Conzelmann, K. K., and Callaway, E. M. (2007). Retrograde neuronal tracing with a deletion-mutant rabies virus. Nat. Methods 4, 47-49. doi: 10.1038/nmeth999

Woo, C. W., Krishnan, A., and Wager, T. D. (2014). Cluster-extent based thresholding in fMRI analyses: pitfalls and recommendations. Neuroimage 91, 412-419. doi: 10.1016/j.neuroimage.2013.12.058

Woolsey, T. A., and Van der Loos, H. (1970). The structural organization of layer IV in the somatosensory region (SI) of mouse cerebral cortex. The description of a cortical field composed of discrete cytoarchitectonic units. Brain Res. 17, 205-242. doi: 10.1016/0006-8993(70)90079-X

Woolsey, T. A., and Wann, J. R. (1976). Areal changes in mouse cortical barrels following vibrissal damage at different postnatal ages. J. Comp. Neurol. 170, 53-66. doi: 10.1002/cne.901700105

Wright, A. K., Norrie, L., and Arbuthnott, G. W. (2000). Corticofugal axons from adjacent 'barrel' columns of rat somatosensory cortex: cortical and thalamic terminal patterns. J. Anat. 196 (Pt 3), 379-390. doi: 10.1046/j.1469-7580.2000.19630379.x

Wu, C. S., Ballester Rosado, C. J., and Lu, H. C. (2011). What can we get from 'barrels': the rodent barrel cortex as a model for studyingthe establishment of neural circuits. Eur. J. Neurosci. 34, 1663-1676. doi: 10.1111/j.1460-9568.2011.07892.x

Yang, P. F., Chen, D. Y., Hu, J. W., Chen, J. H., and Yen, C. T. (2011). Functional tracing of medial nociceptive pathways using activity-dependent manganese-enhanced MRI. Pain 152, 194-203. doi: 10.1016/j.pain.2010. 10.027

Yu, X., Wadghiri, Y. Z., Sanes, D. H., and Turnbull, D. H. (2005). In vivo auditory brain mapping in mice with Mn-enhanced MRI. Nat. Neurosci. 8, 961-968. doi: $10.1038 / \mathrm{nn} 1477$

Zakiewicz, I. M., Bjaalie, J. G., and Leergaard, T. B. (2014). Brain-wide map of efferent projections from rat barrel cortex. Front. Neuroinform. 8:5. doi: $10.3389 /$ fninf.2014.00005

Zeng, W. B., Jiang, H. F., Gang, Y. D., Song, Y. G., Shen, Z. Z., Yang, H., et al. (2017). Anterograde monosynaptic transneuronal tracers derived from herpes simplex virus 1 strain H129. Mol. Neurodegener. 12, 38. doi: 10.1186/s13024-017-0179-7

Zingg, B., Chou, X. L., Zhang, Z. G., Mesik, L., Liang, F., Tao, H. W., et al. (2017). AAV-mediated anterograde transsynaptic tagging: mapping corticocollicular input-defined neural pathways for defense behaviors. Neuron 93, 33-47. doi: 10.1016/j.neuron.2016.11.045

Conflict of Interest Statement: The authors declare that the research was conducted in the absence of any commercial or financial relationships that could be construed as a potential conflict of interest.

Copyright (c) 2018 Almeida-Corrêa, Czisch and Wotjak. This is an open-access article distributed under the terms of the Creative Commons Attribution License (CC $B Y)$. The use, distribution or reproduction in other forums is permitted, provided the original author(s) and the copyright owner are credited and that the original publication in this journal is cited, in accordance with accepted academic practice. No use, distribution or reproduction is permitted which does not comply with these terms. 